NBER WORKING PAPER SERIES

INTEREST-RATE SMOOTHING

Robert J. Barro

Working Paper No. 2581

NATIONAL BUREAU OF ECONOMIC RESEARCH

1050 Massachusetts Avenue

Cambridge, MA 02138

May 1988

The research reported here is part of the NBER's research program in Economic Fluctuations and Financial Markets and Monetary Economics, Any opinions expressed are those of the authors and not those of the National Bureau of Economic Research. 


\section{Interest-Rate Smoothing}

\section{ABSTRACI}

The paper develops a model in which targeting of the nominal interest rate is a reasonable guide for monetary policy. Expected real interest rates and output are exogenous with respect to monetary variables, and the central bank ends up influencing nominal interest rates by altering expected inflation. In this model the monetary authority can come arbitrarily close in each period to its (time-varying) target for the nominal interest rate, even while holding down the forecast variance of the price level. The latter objective pins down the extent of monetary accommodation to shifts in the demand for money and other shocks, and thereby makes determinate the levels of money and prices at each date. Empirical evidence for the United States in the post-Korld har II period suggests that the model's predictions accord reasonably well with observed behavior for nominal interest rates, growth rates of the monetary base, and rates of inflation. Earlier periods, especially before horld War I, provide an interesting contrast because interest-rate smoothing did not apply. The behavior of the monetary base and the price level at these times differed from the post-Horld War II experience in ways predicted by the theory. 
Central bankers, including those at the Federal Reserve, seem to talk mainly in terms of controlling or targeting interest rates. Given the pervasiveness of this outlook, it would probably be useful for economists to assign interest rates a major role in a positive theory of monetary policy. Nevertheless, many monetary theorists-especially those of an "equilibrium" persuasion (and sometimes called "monetarists")-have viewed monetary policy mainly in terms of the behavior of monetary aggregates. In this view the targeting of interest rates is either impossible or undesirable (see, for example, Friedman, 1968, and Brunner, 1968). One aspect of modern versions of this skepticism concerns price-level determinism under an interest-rate rule (see Sargent and Wallace, 1975, and McCallum, 1981), A major result here is that an interest-rate target requires some additional mechanism to pin down the levels of nominal variables. However, this observation does not distinguish an interest-rate rule from rules related to monetary growth or inflation, which may also be incomplete with respect to the levels of money and prices.... In any event, since any of these rules can be extended to achieve price-level determinism, this criticism does not constitute a serious attack on the logic or desirability of this class of policies.

Part of the difficulty in thinking of monetary policy in terms of interest rates concerns the familiar distinction between real and nominal rates. It may be that systematically and significantly influencing expected real interest rates - which is what many macroeconomists imagine when they view monetary policy in terms of interest rates-is beyond the power of monetary authorities over periods of interesting length. In fact, my assumption throughout this paper is that expected real interest rates are exogenous with respect to monetary policy. But even with this extreme assumption about real rates, the nominal interest rate is a perfectly $f$ ine 
nominal variable that the monetary authority ought to be able to control-at least if it does not try simultaneously to regulate some other nominal rate of change, such as the inflation rate, the growth rate of a monetary aggregate, or the rate of change of the exchange rate. Moreover, since interest rates can be observed rapidly and with great accuracy, they are good candidates for variables that the monetary authority conld monitor and react to in a feedback manner. In this respect, feedback from nominal interest rates to monetary instruments seems more attractive than some alternative suggestions that involve the inflation rate or the growth rate of nominal GNP.

In this paper I explore the behavior of monetary policy that is consistent with an objective of interest-rate smoothing. I argue that such an objective appears reasonable, and leads in a theoretical model to welldefined behavior for the monetary base and the price level. Furthermore, this behavior for money and prices provides testable hypotheses about these variables under a regime where the monetary authority targets nominal interest rates. The empirical results suggest that this regime is a good approximation to reality in the United States in the post-World War II period, and perhaps also in the interwar period. The sample before World War I reveals very different behavior for the nominal interest rate, and therefore provides an interesting contrast to the recent experience.

Part I sets out the theoretical model. Part II considers optimal monetary policy within this model. Part III views this optimal policy as a positive theory to derive hypotheses about the behavior of the nominal interest rate, the growth rate of the monetary base, and the inflation rate. Part IV extends the analysis to incorporate seasonal elements. Then Part $Y$ relates the theory to empirical evidence for the United States since 1890 . 


\section{The Basic Theoretical Model}

I use a simple stochastic model of money supply and demand, which builds on models of Goodfriend (1987), McCallum (1986), and Hetzel (1987). The private economy is described by two equations, the first pertaining to interest-rate determination, and the second to the real demand for money:

$$
\begin{aligned}
& \text { (1) } R_{t}=E_{t} p_{t+1}-p_{t}+r_{t}+v_{t} \\
& \text { (2) } m_{t}-p_{t}=a_{t}-\beta R_{t}+\eta_{t}
\end{aligned}
$$

where the variables are

$R_{t}$ : nominal interest rate,

$\mathrm{p}_{\mathrm{t}}: \log$ of price level,

$E_{t} p_{t+1}$ : expectation of next period's $\log$ of price level, based on information available at date $t$,

$m_{t}$ : $\log$ of quantity of money (measured empirically as the monetary base),

$r_{t}$ : "permanent" part of the expected real interest rate,

$v_{t}$ : temporary shock to the expected real interest rate, distributed independently as white noise, (mean 0 , variance $\sigma_{\mathrm{v}}^{2}$ ),

$a_{t}$ : permanent part of level of real demand for money,

$\eta_{\mathrm{t}}$ : temporary shock to real demand for money, distributed independently as white noise, $\left(0, \sigma_{\eta}^{2}\right)$,

$\beta>0$ : coefficient of the nominal interest rate in the money-demand function.

The permanent components of the expected real interest rate and money demand follow random walks, 


$$
\begin{aligned}
& r_{t}=r_{t-1}+w_{t} \\
& a_{t}=a_{t-1}+a_{t}
\end{aligned}
$$

where $w_{t}$ and $a_{t}$ are distributed independently as white noise, (mean 0 , variances $\sigma_{w}^{2}$ and $\sigma_{a}^{2}$, respectively). If the expected real interest rate is stationary, then $\sigma_{w}^{2}=0$.

Equation (1) says that the expected real interest rate, $I_{t}+v_{t}$, is the sum of a random-walk and a wite-noise component. The main restriction in this specification is that movements in the expected real rate are independent of monetary disturbances; that is, of shifts in the demand for money, $a_{t}$ and $\eta_{t}$, or in the supply of nominal money. It is straightforward to allow for nonzero covariances between the shocks to the expected real interest rate and the shocks to money demand. However, it is more important that "monetary policy" cannot affect the expected real interest rate in this model.

The specification of money demand in equation (2) is similar in spirit. The shifts to money demand, $a_{t}$ and $\eta_{t}$, include effects from changes in output (permanent and transitory, respectively). But these changes-and other shifts to the level of the money-demand function-are treated as independent of the behavior of the nominal money stock. However, monetary policy can influence the nominal interest rate, $R_{t}$, and thereby affect the quantity of real money demanded. $\stackrel{I}{-}$ The particular functional form, with the constant semi-elasticity $-\beta$, is solely for analytical convenience.

There are, of course, models in which monetary shocks can affect the expected real interest rate and output. In equilibrium-style frameworks (such as Lucas, 1972, 1973, and Barro, 1976, 1980), the real effects of money depend on incomplete information about monetary aggregates and price levels. 
Since the gaps in information may be small and short lived, the quantitative significance of these effects has often been questioned on a priori grounds. Even when the information lags are important, the direction of effect of money on the real variables is ambiguous (Barro and King, 1984). In any case, the empirical evidence (Barro, 1981a) suggests that the impact of monetary shocks on expected real interest rates is small.

Other models where money has real effects involve the influence of expected inflation on transaction costs and the quantity of real cash balances. However, these channels are usually viewed as quantitatively unimportant. Finally, money may influence the expected real interest rate and output in models with sticky prices, although convincing theoretical accounts of stickiness that matters for real allocations are still absent.

Overall, I treat the expected real interest rate and output as exogenous with respect to money because I lack an alternative specification that I regard as theoretically or empirically superior. However, even if this assumption is wrong, it may still be satisfactory in the present context if money matters mostly for nominal variables-such as the price level and the nominal interest rate-and only secondarily for real variables.

The monetary authority controls the quantity of nominal money (the monetary base), $m_{t}$, in each period. Given the assumed dichotomy between money and real variables, it is difficult to motivate a meaningful objective for the monetary authority. For example, any concern about output and expected real interest rates would not matter for the choice of monetary policy. I assume that the monetary authority cares about two things: first, the departure of the nominal interest rate, $R_{t}$, from a target value, $\bar{R}_{t}$; and second, the spread between the price level, $p_{t}$, and people's prior expectation, $E_{t-1} p_{t}$. In particular, I assume (as detailed below) that the 
authority wants to hold down the magnitudes of the two gaps, $\left|R_{t}-\vec{x}_{t}\right|$ and $\left|p_{t}-E_{t-1} p_{t}\right|$. Fundamentally, these concerns mist reflect some real consequences from the two types of gaps, which implies that monetary policy is not fully neutral. My basic assumption is that these non-neutralities are important enough to motivate an interest in monetary policy, but not important enough to generate significant effects on the time pattern of expected real interest rates and outputs. In particular, the real effects can be neglected for the purpose of using equations (1) and (2) to determine the time path of the price level and the nominal interest rate.

It turns out in this model that the monetary authority can keep the nominal interest rate, $\mathrm{R}_{t}$, close to its target, $\overline{\mathrm{R}}_{t}$, in each period. Therefore, if $\bar{R}_{t}$ were constant, the model would predict little variation in nominal interest rates. But it is well known that, especially in recent years, nominal interest rates move around a good deal and in a largely unpredictable manner. In fact, even for short-term rates, a random walk is a pretty good description of the recent data. In order to accord with this observation, the model incorporates a time-varying target for the nominal interest rate that follows a random walk,

(4) $R_{t}=R_{t-1}+u_{t}$,

where $u_{t}$ is an independent, white-noise process with moments, $\left(0, \sigma_{u}^{2}\right)$.

The subsequent results would change little if equation (4) were modified to $\tilde{\mathrm{R}}_{\mathrm{t}}=\rho \overline{\mathrm{R}}_{\mathrm{t}-1}+\mathrm{u}_{\mathrm{t}}$, where $\rho$ is close to but below unity. The interest-rate target would then have a long-run tendency to revert to a stationary mean. But this change would matter little for the high-frequency properties of the nominal interest rate, monetary growth, and inflation, which are the main 
concerns of this study. In addition, it would be straightforward to allow for nonzero covariances between $u_{t}$ and the other disturbance terms.

One motivation for equation (4) is that the nominal interest rate is the tax rate on money, and the government sets this tax rate as part of an overall problem of optimal public finance. The desire to smooth taxes intertemporally, as stressed in Barro (1979) and Mankiw (1987), tends also to motivate smoothness in individual components of the tax package, such as the tax rate on money. 2 In this context smoothness means that the government avoids predictable movements up and down of the tax rates. Consequently, tax rates-here the target nominal interest rate, $\overline{\mathrm{R}}_{t}$-would follow a Martingale process, as implied by the random-walk model in equation (4).

Many economists are understandably skeptical that this optimal-tax argument is a major element in the conduct of monetary policy in the United States or many other countries. However, for subsequent purposes, the only significant consideration is that policy involve an interest-rate target, $\vec{R}_{t}$, that shifts unpredictably over time. This behavior could likely be motivated by models of monetary policy that have nothing to do with $f$ iscal concerns.

Because of the lower bound of zero on the nominal interest rate, equation (4) cannot apply universally. However, a random walk may be a satisfactory approximation for a broad range of nominal interest rates, even if not for samples (such as that for the 1940s and early 1950 s in the United States) where the rates get close to zero.

I assume that the monetary anthority and the private agents have symmetric information, with each observing $m_{t}, R_{t}$, and $\bar{R}_{t}$ during period $t$. In contrast, observations on the price level arise with a lag (say 1 to 2 months for accurate indices). I model this information lag by assuming that 
data on $p_{t-1}$ become available during period $t .^{3}$ Therefore, the lag in obtaining data on the general price level essentially defines the length of the period in the model. This setup accords with the notion that interest rates are observable more rapidly (and with greater accuracy) than are price indices. Also, the approach embodies the idea that the lag in pubitishing figures on the money stock (say the monetary base) is short enough to neglect. $\underline{4}$

A number of economists (such as Brunner, Cukierman, and Meltzer, 1980) stress that the monetary authority cannot readily distinguish permanent shifts to money demand from temporary shifts. I model this problem by assuming that information about the permanent shock arrives with a one-period lag; that is, $\alpha_{\mathrm{t}-1}$ is known at date $\mathrm{t}$. More realistically, the $\alpha^{\prime} \mathrm{s}$ would never be observed directly, and estimates of $\alpha_{\mathrm{t}-1}$ (formed at date $t$ ) would utilize the observed time series of real cash balances, $m_{t-1}-p_{t,-1}$, $m_{t-2}-p_{t-2}$, etc. The inclusion of $a_{t-1}$ in date $t^{t} s$ information set is a tractable approximation to this specification. Similarly, I assume that people observe the permanent component of the expected real interest rate with a one-period lag; that is, $r_{t-1}$ is known at date $t$.

Given this informational setup, the monetary authority's optimal choice of $m_{t}$ can be expressed as a function of the state of the economy at date $t$. Because the model is linear and the monetary authority's objective is assumed (below) to be quadratic, the optimal rule would be a linear function of the state of the economy. In particular, monetary growth can be written in the form $m^{5}$

(5) $\mathrm{m}_{\mathrm{t}}-\mathrm{m}_{\mathrm{t}-1}=\lambda_{0}+\lambda_{1} \mathrm{R}_{\mathrm{t}}+\lambda_{2} \overline{\mathrm{R}}_{\mathrm{t}}+\lambda_{3} \mathrm{R}_{\mathrm{t}-1}+\lambda_{4} \overline{\mathrm{R}}_{\mathrm{t}-1}+\lambda_{5} \alpha_{\mathrm{t}-1}+\lambda_{6} a_{\mathrm{t}-2}$ $+\lambda_{7} r_{t-1}$ 
The coefficients $\lambda$ will be determined by the policymaker's optimization problem.

Yany macroeconomic models can be thought of in terms of the sign of $\lambda_{1}$ starting from $R_{t}=\bar{R}_{t}$ and for given $\bar{R}_{t}$, if $R_{t}$ rises do you print more money $\left(\lambda_{1}>0\right)$ or less money $\left(\lambda_{1}<0\right)$ to get $R_{t}$ back down to target? The condition $\lambda_{1}>0$ (which central bankers know is right, and which in fact applies in this model) tends to arise in Keynesian models where monetary expansion has an inverse effect on the expected real interest rate. But, in the present model, the expected real interest rate is exogenous. Therefore, a positive response of $m_{t}-m_{t-1}$ to an increase in $R_{t}\left(\lambda_{1}>0\right)$ can work to reduce $R_{t}$ in this model only if expected inflation, $E_{t} p_{t+1}-p_{t}$, declines. $\underline{6}$ This reduction in expected inflation tends to occur if expected future monetary growth, $\mathrm{E}_{\mathrm{t}} \mathrm{m}_{\mathrm{t}+1^{-\mathrm{m}_{t}}}$, falls. In other words, an increase in $\mathrm{R}_{\mathrm{t}}$ must create a tendency for some of today's infusion of money to be taken back in the future; for example, in the next period. This effect follows from the term, $\lambda_{3} R_{t-1}$ in equation (5), if $\lambda_{3}<0$. In fact, it is the negative value of $\lambda_{3}$, and not the value of $\lambda_{1}$, that matters for interest-rate targeting. The value of $\lambda_{1}$ is irrelevant in this context because it turns out to affect equally the levels of money (and prices) for periods $t$ and $t+1$. However, the choice of $\lambda_{1}$ matters if the monetary authority cares not only about targeting nominal interest rates, but also-as I assume-about the predictability of the price level. This last consideration will pin down the desired response of today ${ }^{\dagger} \mathrm{s}$ money to today's interest rate, which then determines the value of $\lambda_{1}$, and thereby makes determinate the levels of money and prices at each date. For this reason, the problem of price-level indeterminism (as discussed in Sargent and Wallace, 1975; and McCallum, 1981) will not arise here. 
The linear model described by equations (1)-(5) can be solved (after a lot of algebra) in the usual way by the method of undetermined coefficients (see Lucas, 1973, Barro, 1976, McCallum, 1983, 1986, and Goodfriend, 1987). The main complication is that the expected price level. $E_{t} p_{t+1}$ in equation (1), depends on the expectations, $E_{t} a_{t}$ and $E_{t} w_{t}$. That is, lacking full current information about this period's permanent shocks to money demand and the expected real interest rate- $a_{t}$ and $w_{t}$-people form expectations conditioned on limited current information. This information is conveyed by observing today ${ }^{\prime}$ nominal interest rate, $R_{t}$; and money stock, $m_{t}$. (Recall that $p_{t}$ is not observable at date $t$.)

In any event, the result from this exercise is an equilibrium solution for $R_{t}, p_{t}$ and $m_{t}$ as linear functions of current shocks, $\left(a_{t}, \eta_{t}, w_{t}, v_{t}, u_{t}\right)$, and lagged variables. $\underline{7}$ The results involve the $8 \lambda$-coefficients that characterize monetary policy in equation (5).

\section{Monetary Policy}

Given the equilibrium solution described in Section $I$, the monetary authority chooses its policy coefficients, $\lambda_{0}, \ldots, \lambda_{7}$, to minimize the expression,

$$
\text { (6) } A \bullet E\left(R_{t}-\bar{R}_{t}\right)^{2}+B \cdot E\left(p_{t}-E_{t-1} p_{t}\right)^{2} \text {, }
$$

where $A$ and $B$ are positive constants. The objective penalizes interest-rate gaps and price-level surprises in the typical future period, which is well defined because the two expectations of squared gaps in expression (6) end up 
being the same for all dates $t$. (The results would not change if the objective involved an expected present value of the terms shown in equation (6).)

Instead of examining the solution to the model for arbitrary choices of the $\lambda$-coefficients, I begin with the optimizing conditions that are intuitive, and then use these restrictions to collapse the equilibrium solution to a manageable form. Recall that equation (5) is

$$
m_{t}-m_{t-1}=\lambda_{0}+\lambda_{1} R_{t}+\lambda_{2} \vec{R}_{t}+\lambda_{3} R_{t-1}+\lambda_{4} \bar{R}_{t-1}+\lambda_{5} \alpha_{t-1}+\lambda_{6} \alpha_{t-2}+\lambda_{7} r_{t-1}
$$

The policymaker's optimization implies the following conditions:

1) $\lambda_{1}+\lambda_{2}+\lambda_{3}+\lambda_{4}=1$-in the long run, a higher value of nominal interest rates and nominal-interest-rate targets must, for a given expected real rate, correspond one-to- one to a higher monetary growth rate (if not, the term, $E\left(R_{t}-\bar{R}_{t}\right)^{2}$, is unbounded as $\left.t \rightarrow \infty\right)$.

2) $\lambda_{7}=-1$-given the long-term behavior of nominal interest rates, an increase in the permanent component of the expected real rate implies a one-to-one reduction of the inflation rate, and hence, of the monetary growth rate (again needed to keep $E\left(R_{t}-\bar{R}_{t}\right)^{2}$ bounded).

3) $\lambda_{0}=0-$ whthout sustained real growth, monetary growth corresponds in the long run to the inflation rate, and hence to the difference between the nominal and expected real interest rates; more generally, $\lambda_{0}$ equals the long-term growth rate of real money demanded (this condition keeps down $E\left(R_{t}-\bar{R}_{t}\right)^{2}$ with no implications for $\left.p_{t}-E_{t-1} p_{t}\right)$.

4) $\lambda_{5}=-\lambda_{6}=1$-the first part, $\lambda_{5}=-\lambda_{6}$, is necessary to keep $E\left(R_{t}-\vec{R}_{t}\right)^{2}$ bounded as $t \rightarrow \infty$; the second part says that permanent shifts to money demand, $a_{t-1}=a_{t-1}-a_{t-2}$, are fully accommodated once they are 
recognized as permanent. This response holds down $E\left(p_{t}-E_{t-1} p_{t}\right)$ without affecting $R_{t}-\bar{R}_{t}$.

Given conditions (1)-(4), the form for the monetary growth rate can be written as

$$
\begin{aligned}
m_{t}-m_{t-1}=\lambda_{1}\left(R_{t}-\bar{R}_{t}\right) & +\lambda_{3}\left(R_{t-1}-\bar{R}_{t-1}\right)+\bar{R}_{t-1}+\left(\lambda_{1}+\lambda_{2}\right)\left(\bar{R}_{t}-\bar{R}_{t-1}\right) \\
& +a_{t-1}-r_{t-1}
\end{aligned}
$$

The next optimizing condition is

5) $\lambda_{1}+\lambda_{2}=-\beta-a$ (permanent) shift in the target, $u_{t}=\bar{R}_{t}-\bar{R}_{t-1}$ (and hence, in actual nominal interest rates, which are being targeted), depresses real money demanded by the amount $-\beta$. The reduction in monetary growth by this amount avoids a price level response and, therefore, holds down $E\left(p_{t}-E_{t-1} p_{t}\right)$ (without affecting $\left.R_{t}-\bar{R}_{t}\right)$.

Given conditions (1)-(5), the monetary growth rate is given by

(7) $m_{t}-m_{t-1}=\lambda_{1}\left(R_{t}-\bar{R}_{t}\right)+\lambda_{3}\left(R_{t-1}-\bar{R}_{t-1}\right)+\bar{R}_{t-1}-\beta u_{t}+a_{t-1}-r_{t-1}$

This form highlights the role of the coefficients $\lambda_{1}$ and $\lambda_{3}$, which describe monetary reactions to current and lagged interest-rate gaps. Corresponding to equation (7), the model's equilibrium solution can be used to derive the following results:

$$
\text { (8) } R_{t}-\bar{R}_{t}=\frac{\left(\eta_{t}+a_{t}+v_{t}+w_{t}\right)}{\left(1-\lambda_{3}+\beta\right)}
$$




$$
\text { (9) } p_{t}-E_{t-1} p_{t}=-\frac{\left(\eta_{t}+a_{t}\right)\left(1-\lambda_{1}-\lambda_{3}\right)}{\left(1-\lambda_{3}+\beta\right)}+\frac{\left(v_{t}+w_{t}\right)\left(\lambda_{1}+\beta\right)}{\left(1-\lambda_{3}+\beta\right)}
$$

Since the economy cannot distinguish in the current period between temporary and permanent shocks, the two money-demand disturbances enter as the sum, $\eta_{t}$ $+a_{t}$, and the two real-interest-rate disturbances enter as the sum, $v_{t}+w_{t}$. In the absence of a monetary response, a positive shock to money demand, $\eta_{t}+a_{t}$, lowers $p_{t}-E_{t-1} p_{t}$. To the extent that the economy views the shock as temporary, $E_{t} p_{t+1}-p_{t}$ rises (that is, the temporary disturbance would not affect $E_{t} P_{t+1}$ ), so that $R_{t}-\bar{R}_{t}$ increases. The reaction, $\lambda_{1}$, of $m_{t}-m_{t-1}$ to $R_{t}-\bar{R}_{t}$ offsets the tendency of $p_{t}-E_{t-1} p_{t}$ to fall in equation (9). If $\lambda_{3}<0$, the negative reaction of $m_{t+1}-m_{t}$ lowers $E_{t} p_{t+1}-p_{t}$ and thereby reduces $R_{t}-\vec{R}_{t}$ in equation (8).

A positive shock to the expected real interest rate, $v_{t}+w_{t}$, raises $R_{t}-\vec{R}_{t}$ directly in equation (8). The reaction of monetary growth, $\lambda_{1}$, and the reduction in money demand, $\beta$, lead to increases in $p_{t}-E_{t-1} P_{t}$ in equation (9). To the extent that $m_{t+1}-m_{t}$ declines (with $\lambda_{3}<0$ ), the response of $R_{t}-\bar{R}_{t}$ to $v_{t}+w_{t}$ gets smaller in equation (8).

Def ine the overall variance of money-demand and real-interest-rate shocks as

$$
\text { (10) } \sigma^{2} \equiv \sigma_{\eta}^{2}+\sigma_{\mathrm{a}}^{2}+\sigma_{\mathrm{v}}^{2}+\sigma_{\mathrm{w}}^{2}
$$

The results in equations (8) and (9) imply that the terms appearing in the policymaker's objective in equation (6) are given by 


$$
\begin{gathered}
\text { (11) } E\left(\mathrm{R}_{\mathrm{t}}-\overline{\mathrm{a}}_{\mathrm{t}}\right)^{2}=\frac{\sigma^{2}}{\left(1-\lambda_{3}+\beta\right)^{2}} \\
\text { (12) } E\left(\mathrm{p}_{\mathrm{t}}-\mathrm{E}_{\mathrm{t}-1} \mathrm{p}_{\mathrm{t}}\right)^{2}=\frac{\left(\sigma_{\eta}^{2}+\sigma_{\mathrm{a}}^{2}\right)\left(1-\lambda_{1}-\lambda_{3}\right)^{2}}{\left(1-\lambda_{3}+\beta\right)^{2}}+\frac{\left(\sigma_{\mathrm{v}}^{2}+\sigma_{\mathrm{w}}^{2}\right)\left(\lambda_{1}+\beta\right)^{2}}{\left(1-\lambda_{3}+\beta\right)^{2}}
\end{gathered}
$$

Note that $E\left(R_{t}-\bar{R}_{t}\right)^{2}$ in equation (10) is independent of $\lambda_{1}$. (The contemporaneous reaction, $\lambda_{1}$, of money to the interest rate affects the levels of money and prices, but not the rates of change that matter for the nominal interest rate.) Hence, $\lambda_{1}$ can be chosen to minimize $E\left(p_{t}-E_{t-1} p_{t}\right)^{2}$ for a given value of $\lambda_{3}$. In particular, the solution for $\lambda_{1}$ as a function of $\lambda_{3}$ does not depend on the weights, $A$ and $B$, in expression (6). The resulting condition is

$$
\text { (13) } \lambda_{1}=\frac{\left(1-\lambda_{3}\right)\left(\sigma_{\eta}^{2}+\sigma_{\mathrm{a}}^{2}\right)-\beta\left(\sigma_{\mathrm{v}}^{2}+\sigma_{\mathrm{v}}^{2}\right)}{\sigma^{2}}
$$

Given this choice for $\lambda_{1}$ as a function of $\lambda_{3}, E\left(p_{t}-E_{t-1} p_{t}\right)^{2}$ in equation (12) becomes

$$
\text { (14) } E\left(p_{\mathrm{t}}-E_{\mathrm{t}-1} \mathrm{P}_{\mathrm{t}}\right)^{2}=\frac{\left(\sigma_{\eta}^{2}+\sigma_{\mathrm{a}}^{2}\right)\left(\sigma_{\mathrm{v}}^{2}+\sigma_{\mathrm{w}}^{2}\right)}{\sigma^{2}}
$$

which is independent of $\lambda_{3}$. As long as the current and prospective reactions of money to interest-rate gaps, $\lambda_{1}$ and $\lambda_{3}$, maintain the correct relationship -dictated by equation (13)-the overall level of the reaction does not matter for the determination of $p_{t}$. Therefore, $\lambda_{3}$ can now be chosen 
(independently of the weights $A$ and $B$ in expression (6)) to minimize $E\left(R_{t}-\bar{R}_{t}\right)^{2}$. It follows immediately from equation (11) that the best choice is $\lambda_{3}+-\infty$ Equation (13) then implies $\lambda_{1}+\infty$, but the ratio, $\lambda_{1} / \lambda_{3}$, remains finite and is given by

$$
\text { (15) } \frac{\lambda_{1}}{\lambda_{3}}=-\frac{\left(\sigma_{\eta}^{2}+\sigma_{\mathrm{a}}^{2}\right)}{\sigma^{2}}
$$

- that is, as the ratio of money-demand variance to the sum of money-demand and expected-real-interest-rate variance. Hence $0 \leq\left|\lambda_{1} / \lambda_{3}\right| \leq 1$-the current reaction of money to the nominal interest rate is smaller in magnitude and opposite in sign to the prospective reaction. However, in the limit, each reaction become infinite in order to keep the nominal interest rate, $\mathbb{R}_{t}$, arbitrarily close to its target, $\bar{R}_{t}$, in each period.

Using the form of the monetary rule from equation (7) and the optimal choices for $\lambda_{1}$ and $\lambda_{3}$, the equilibrium solutions for $R_{t}, p_{t}$, and $m_{t}$ turn out to be

(16) $\quad R_{t}=R_{t}=R_{t-1}+u_{t}$

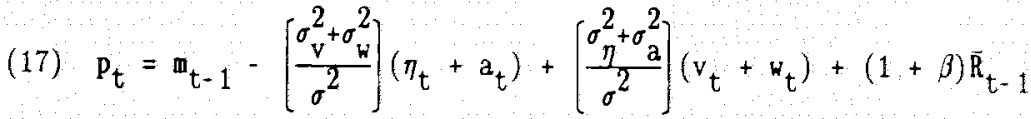

$$
-\left(\eta_{t-1}+v_{t-1}\right)-\alpha_{t-1}-r_{t-1}
$$




$$
\begin{aligned}
\mathrm{m}_{\mathrm{t}}=\mathrm{m}_{\mathrm{t}-1} & +\left[\frac{\sigma^{2}+\sigma_{a}^{2}}{\sigma^{2}}\right]\left(\eta_{t}+a_{t}+v_{t}+w_{t}\right)-\beta u_{t}+\overline{\mathrm{R}}_{\mathrm{t}-1} \\
& -\left(\eta_{t-1}+v_{t-1}\right)-r_{t-1}
\end{aligned}
$$

Equation (18) shows that monetary growth partially accommodates the current shocks to money demand and the expected real interest rate, $\eta_{t}+a_{t}+v_{t}+k_{t}$; that is, the coefficient is $\left(\sigma_{\eta}^{2}+\sigma_{a}^{2}\right) / \sigma^{2}$ (where $\sigma^{2}$ is the total variance). The result says that contemporaneous monetary accommodation is greater the larger the variance of money demand $\left(\sigma_{\eta}^{2}+\sigma_{a}^{2}\right)$ relative to that of the expected real interest rate $\left(\sigma_{\mathrm{v}}^{2}+\sigma_{\mathrm{w}}^{2}\right)$. Interpreting $\sigma_{\eta}^{2}+\sigma_{\mathrm{a}}^{2}$ as the variance of the LY curve and $\sigma_{v}^{2}+\sigma_{y}^{2}$ as the variance of the IS curve, the results are reminiscent of those found by Poole (1970). However, in the present model, the tradeoff is not between targeting nominal interest rates and targeting monetary aggregates. The targeting of the nominal interest rate is complete here independently of the variances of money demand and the expected interest rate (that is, of the relative volatility of the LM and IS curves). In the present model, the tradeoff that determines the extent of current accommodation comes, in equation (17), from the negative response of $\mathrm{p}_{\mathrm{t}}$ to the money-demand shock, $\eta_{t}+\mathrm{a}_{\mathrm{t}}$, and the positive response to the real-interest-rate shock, $v_{t}+w_{t}$. (The former reflects the negative effect on prices from an increase in money demand less the positive effect from the monetary response. The latter reflects only the monetary reaction.) The extent of monetary accommodation is the one that makes the overall variance of $p_{t}$ from these two sources of disturbances as small as possible.

With a one-period lag, monetary growth exhibits an inverse, one-to-one reaction to the temporary shocks $\left(\eta_{t-1}+v_{t-1}\right.$ in equation (18)). This response generates the reduction in expected inflation that allows the 
monetary authority to offset an incipient excess of $R_{t}$ over $R_{t}$. In particular, although the temporary shock, $\eta_{t}+v_{t}$, induces an increase in today's monetary growth, it also generates a reversal pattern where next period's monetary growth falls by more than today's increase.

A permanent shock to money demand, $a_{t}=\alpha_{t}-\alpha_{t-1}$, is accommodated partially (since it cannot be disentangled from a temporary shock), but there is no adjustment of monetary growth at date $t+1$ when the value of $a_{t}$ is revealed. Hence the reversal pattern for monetary growth does not arise for permanent shifts to money demand. (If $a_{t}$ were observable at date $t$, money growth would react one-to-one immediately, and subsequent growth rates of money would be unchanged.)

Finally, a shock to the interest-rate target, $u_{t}=R_{t}-R_{t-1}$-which $I$ assume is observable at date t-affects monetary growth by the amount $-\beta$, and thereby leaves $p_{t}$ unchanged... (If any of the other disturbances- $\eta_{t}, a_{t}, v_{t}$, $w_{t}$-were observable, the policymaker could similarly insulate the price level from these shocks.)

One of the prime sources of shifts to money demand, $\eta_{t}+a_{t}$, would be movements in output. The results in equations (17) and (18) imply (for a given expected real interest rate) that these exogenous shifts in output would be contemporaneously negatively correlated with the price level and contemporaneously positively correlated with the money supply. Thus the results are consistent with Fair's (1979) findings about the relation between shocks to output and prices for the United States in the post-Horld War II period. Also, the results accord with many analyses that report a positive correlation between money and output, although the relation in this model reflects only the endogenous response of the money supply (which has been 
stressed by King and Plosser, 1984). On the other hand, lagged output (that is, $\eta_{\mathrm{t}-1}$ ) would be negatively correlated with current money (and prices). This result means that monetary growth would exhibit a countercyclical reaction to lagged output. This type of relation has been found for $M 1$ growth in the post-World War II United States in Barro (1981b).

\section{Implications of the Theory for Monetary-Base Growth and Inflation}

Let $\Delta R_{t}=R_{t}-R_{t-1}, \Delta n_{t}=m_{t}-m_{t-1}$ (the growth rate of the monetary base), and $\Delta \mathrm{p}_{\mathrm{t}}=\mathrm{p}_{\mathrm{t}}-\mathrm{p}_{\mathrm{t}-1}$ (the inflation rate). Equation (16) implies that $\Delta \mathrm{R}_{\mathrm{t}}$ is white noise. (If $\bar{R}_{t}$ were not a random walk, but instead had a mean-reverting tendency in the long run, then the process for $\mathrm{R}_{t}$ would change accordingly.) Equations (17) and (18) prescribe the patterns for $\Delta \mathrm{p}_{t}$ and $\Delta \mathrm{m}_{t}$ that are consistent with this process for $\Delta R_{t}$. These predictions about inflation and monetary-base growth are the principal empirical content of the theory.

Taking first differences of equation (18) leads to

$$
\text { (19) } \begin{aligned}
\Delta \mathrm{m}_{\mathrm{t}} & =\Delta \mathrm{m}_{\mathrm{t}-1}+\left[\frac{\sigma^{2}+\sigma_{\mathrm{a}}^{2}}{\sigma^{2}}\right]\left(\eta_{\mathrm{t}}+\mathrm{a}_{\mathrm{t}}+\mathrm{v}_{\mathrm{t}}+\mathrm{w}_{\mathrm{t}}\right)-\beta \mathrm{u}_{\mathrm{t}}-\left[\frac{\sigma_{\eta}^{2}+\sigma_{\mathrm{a}}^{2}}{\sigma^{2}}\right] \mathrm{a}_{\mathrm{t}-1} \\
& -\left[1+\frac{\sigma^{2}+\sigma_{\mathrm{a}}^{2}}{\sigma^{2}}\right]\left(\eta_{\mathrm{t}-1}+\mathrm{v}_{\mathrm{t}-1}+\mathrm{w}_{\mathrm{t}-1}\right)+(1+\beta) \mathrm{u}_{\mathrm{t}-1}+\left(\eta_{\mathrm{t}-2}+\mathrm{v}_{\mathrm{t}-2}\right) \\
& =\Delta \mathrm{m}_{\mathrm{t}-1}+\mathrm{E}_{\mathrm{t}}=\Delta \mathrm{m}_{\mathrm{t}-1}+\mathrm{e}_{\mathrm{t}}+\mathrm{a}_{1} \mathrm{e}_{\mathrm{t}-1}+\mathrm{a}_{2} \mathrm{e}_{\mathrm{t}-1}
\end{aligned}
$$

where $E_{t}$ is a composite error term and $e_{t}$ is a white-noise disturbance. In other words, the model implies that $\Delta m_{t}$ is an ARIMA $(0,1,2)$ process. Furthermore, the theory imposes restrictions on the coefficients of this 
process. The unitary coefficient on $\Delta m_{t-1}$ reflects the nonstationarity in monetary growth that is induced by the nonstationarity of the nominal-interest-rate target in equation (4) (and also by any nonstationarity of the expected real interest rate in equation (3)).

The two MA coefficients must satisfy the conditions,

(20) $\mathrm{a}_{1}\left(1+\mathrm{a}_{2}\right) \sigma_{\mathrm{e}}^{2}=\operatorname{cov}\left(\mathrm{E}_{\mathrm{t}}, \mathrm{E}_{\mathrm{t}-1}\right)=-\left[\frac{\sigma_{\eta}^{2}+\sigma_{\mathrm{a}}^{2}}{\sigma^{2}}\right]^{2} \sigma_{\mathrm{a}}^{2}-\left[1+\frac{\sigma_{\eta}^{2}+\sigma_{\mathrm{a}}^{2}}{\sigma^{2}}\right]^{2}\left(\sigma_{\eta}^{2}+\sigma_{\mathrm{v}}^{2}\right)$ $-\left[\frac{\sigma_{\mathrm{a}}^{2}+\sigma_{\eta}^{2}}{\sigma^{2}}\right]\left[1+\frac{\sigma_{\mathrm{a}}^{2}+\sigma_{\eta}^{2}}{\sigma^{2}}\right] \sigma_{\mathrm{w}}^{2}-\beta(1+\beta) \sigma_{\mathrm{u}}^{2} \leq 0$

(21) $\mathrm{a}_{2} \sigma_{\mathrm{e}}^{2}=\operatorname{Cov}\left(\mathrm{E}_{\mathrm{t}}, \mathrm{E}_{\mathrm{t}-2}\right)=\frac{\left(\sigma_{\eta}^{2}+\sigma_{\mathrm{a}}^{2}\right)\left(\sigma_{\eta}^{2}+\sigma_{\mathrm{v}}^{2}\right)}{\sigma^{2}} \geq 0$

where $\sigma_{e}^{2}$ is the variance of $e_{t}$. Hence, $a_{1} \leq 0$ and $a_{2} \geq 0$. Moreover, the magnitude of $a_{1}$ is much greater than that of $a_{2} \longrightarrow$ one inequality that holds is $\left|a_{1}\right| \geq 4 a_{2} /\left(1+a_{2}\right)$, or equivalently, $a_{2} \leq\left|a_{1}\right| /\left(4-\left|a_{1}\right|\right)$. As $\sigma_{u}^{2}$ and $\sigma_{w}^{2}$ become small, the solution approaches stationarity for $\bar{R}_{t}$ and $r_{t}$, and hence for monetary growth and inflation. In particular, as $\sigma_{u}^{2}$ and $\sigma_{u}^{2}$ approach zero, the solution tends toward $a_{1}+a_{2}=-1$.

The equation for the inflation rate comes from first differencing of equation (17). After substituting for $\Delta m_{t-1}$ on the right side (using equation (18)) and simplifying, the results are 


$$
\text { (22) } \begin{aligned}
& \Delta \mathrm{p}_{\mathrm{t}}=\Delta \mathrm{p}_{\mathrm{t}-1}-\left[\frac{\sigma_{\mathrm{v}}^{2}+\sigma_{\mathrm{t}}^{2}}{\sigma^{2}}\right]\left(\eta_{\mathrm{t}}+\mathrm{a}_{\mathrm{t}}\right)+\left[\frac{\sigma^{2}+\sigma^{2}}{\sigma^{2}}\right]\left(\mathrm{v}_{\mathrm{t}}+\mathrm{w}_{\mathrm{t}}\right) \\
&+\left[\frac{\sigma_{\mathrm{v}}^{2}+\sigma_{\mathrm{t}}^{2}}{\sigma^{2}}\right]\left(\eta_{\mathrm{t}-1}+\mathrm{a}_{\mathrm{t}-1}\right) \\
&-\left[1+\frac{\sigma_{\eta}^{2}+\sigma_{\mathrm{a}}^{2}}{\sigma^{2}}\right]\left(\mathrm{v}_{\mathrm{t}-1}+\mathrm{w}_{\mathrm{t}-1}\right)+\mathrm{u}_{\mathrm{t}-1}+\mathrm{v}_{\mathrm{t}-2} \\
&=\Delta \mathrm{p}_{\mathrm{t}-1}+\mathrm{F}_{\mathrm{t}}=\Delta \mathrm{p}_{\mathrm{t}-1}+\mathrm{f}_{\mathrm{t}}+\mathrm{b}_{1} \mathrm{f}_{\mathrm{t}-1}+\mathrm{b}_{2} \mathrm{f}_{\mathrm{t}-2}
\end{aligned}
$$

where $F_{t}$ is a composite error term and $f_{t}$ is a wite-noise disturbance (which is not generally independent of $\left.e_{t}\right)$. As before, $\Delta p_{t}$ is an ARIMA $(0,1,2)$ process; the unitary coefficient on $\Delta \mathrm{p}_{\mathrm{t}-1}$ again reflects mainly the nonstationarity of the nominal-interest-rate target. The two HA coefficients satisfy

$$
\text { (23) } \begin{aligned}
\mathrm{b}_{1}\left(1+\mathrm{b}_{2}\right) \sigma_{\mathrm{f}}^{2} & =\operatorname{Cov}\left(\mathrm{F}_{\mathrm{t}}, \mathrm{F}_{\mathrm{t}-1}\right)=-\left[\frac{\sigma_{\mathrm{v}}^{2}+\sigma_{\mathrm{w}}^{2}}{\sigma^{2}}\right]^{2}\left(\sigma_{\eta}^{2}+\sigma_{\mathrm{a}}^{2}\right) \\
& -\left[\frac{\sigma_{\eta}^{2}+\sigma_{\mathrm{a}}^{2}}{\sigma^{2}}\right]\left[1+\frac{\sigma_{\eta}^{2}+\sigma_{\mathrm{a}}^{2}}{\sigma^{2}}\right]\left(\sigma_{\mathrm{v}}^{2}+\sigma_{\mathrm{w}}^{2}\right) \\
& {\left[1+\frac{\sigma_{\eta}^{2}+\sigma_{\mathrm{a}}^{2}}{\sigma^{2}}\right] \sigma_{\mathrm{v}}^{2} \leq 0 }
\end{aligned}
$$




$$
\mathrm{b}_{2} \sigma_{\mathrm{f}}^{2}=\operatorname{Cov}\left(\mathrm{F}_{\mathrm{t}}, \mathrm{F}_{\mathrm{t}-2}\right)=\left[\frac{\sigma^{2}+\sigma_{\mathrm{a}}^{2}}{\sigma^{2}}\right] \sigma_{\mathrm{v}}^{2} \geq 0
$$

where $\sigma_{\mathrm{f}}^{2}$ is the variance of $\mathrm{f}_{\mathrm{t}}$. Hence, $\mathrm{b}_{1} \leq 0$ and $b_{2} \geq 0$. The magnitude of $b_{1}$ tends to be much greater than that of $b_{2}$, with $\left|b_{1}\right| \geq 4 b_{2} /\left(1+b_{2}\right)$ applying. Again, $\sigma_{\mathrm{u}}^{2}=\sigma_{\mathrm{w}}^{2}=0$ implies $\mathrm{b}_{1}+\mathrm{b}_{2}=-1$.

The precise forms of the time-series processes for $\Delta \mathrm{m}_{t}$ and $\Delta \mathrm{p}_{t}$ depend on the distributional specifications for the underlying stochastic shocks. Furthermore, the results are sensitive to discrepanies between the period in the theory and that in a data set. However, the general nature of the results should be robust to these problems. Namely, first, monetary growth and inflation have a unit root if there is a unit root in the nominal interest rate; second, monetary growth and inflation each have a reversal pattern, which shows up with a short lag as a negative and substantial moving-average term; and third, a weaker but positive moving-average term appears at a longer lag.

One other result involves a comparison of the variance of $R_{t}-R_{t-1}$ given from equation (16) as $\sigma_{u}^{2}$-with the one-period variances of monetary growth and inflation. Inspection of equation (22) shows that the variance of $\Delta \mathrm{p}_{\mathrm{t}}-\Delta \mathrm{p}_{\mathrm{t}-1}$ involves $\sigma_{\mathrm{u}}^{2}$ plus other positive terms - therefore, this variance $\left(\operatorname{VAR}\left(F_{t}\right)\right)$ exceeds that of $R_{t}-R_{t-1}$. Similarly, equation (19) implies that the variance of $\Delta m_{t}-\Delta m_{t-1}\left(\operatorname{VAR}\left(E_{t}\right)\right)$ exceeds $\sigma_{u}^{2}$ Hence the model predicts that inflation and monetary growth are each more volatile than the nominal interest rate. This result seems to conflict with the common view that inflation moves relatively little in the short run. However, the prediction turns out to accord with the data. 


\section{Seasonals}

So far, the model contains no systematic seasonals, but these are known to be important for money in the post-world har II period, and for nominal interest rates before the founding of the Federal Reserve (see, for example, Kemmerer, 1910, Ch. 2; Macaulay, 1938, Chart 20; Shiller, 1980, pp. 136-137; Clark, 1986; Miron, 1986; and Mankiw, Miron and Weil, 1986). I consider briefly here the implications of systematic seasonals in money demand and in the real interest rate. For simplicity, I now neglect the various stochastic terms considered before. Given the linearity of the model, the new effects would be additive to those from the stochastic terms.

The model with deterministic seasonals and no stochastic shocks is

$$
\begin{aligned}
& \text { (25) } \mathrm{R}_{\mathrm{t}}=r+\mathrm{p}_{\mathrm{t}+1}-\mathrm{p}_{\mathrm{t}}+\mathrm{T}_{\mathrm{t}} \\
& \text { (26) } \mathrm{m}_{\mathrm{t}}-\mathrm{p}_{\mathrm{t}}=\alpha-\beta \mathrm{R}_{\mathrm{t}}+\mathrm{S}_{\mathrm{t}} \\
& \text { (27) } \mathrm{m}_{\mathrm{t}}-\mathrm{m}_{\mathrm{t}-1}=\mu+\Sigma_{\mathrm{t}}
\end{aligned}
$$

where $T_{t}, S_{t}$, and $\Sigma_{t}$ are seasonal factors, and $E_{t} p_{t+1}=p_{t+1}$ applies in this deterministic model. Suppose, as has been argued is true of the Federal Reserve, that the monetary authority sets $\Sigma_{t}$ to offset the effects of $T_{t}$ and $S_{t}$ on the nominal interest rate. Then, with $R_{t}=\bar{R}$, equation (25) implies

$$
p_{t+1}-p_{t}=\pi-r-T_{t}
$$


Using $R_{t}=\bar{R}$, equation (26) implies

$$
m_{t}-m_{t-1}=p_{t}-p_{t-1}+S_{t}-S_{t-1}
$$

Substituting into this last relation for $p_{t}{ }^{-} p_{t-1}$ from above (with a one-period lag) and for $\mathbf{m}_{t}{ }^{-m_{t-1}}$ from equation (27) yields (after setting $\mu=\bar{R}-\mathrm{r})$

$$
\Sigma_{t}=-T_{t-1}+S_{t}-S_{t-1}
$$

This seasonal pattern for monetary growth eliminates the seasonal in the nominal interest rate-that is, achieves $R_{t}=\bar{R}$.

The implied relations for monetary growth and inflation are

$$
\begin{gathered}
\text { (28) } \Delta \mathrm{m}_{\mathrm{t}}=\mu-\mathrm{T}_{\mathrm{t}-1}+\mathrm{S}_{\mathrm{t}}-\mathrm{S}_{\mathrm{t}-1} \\
\text { (29) } \Delta \mathrm{p}_{\mathrm{t}}=\mu-\mathrm{T}_{\mathrm{t}-1}
\end{gathered}
$$

Note that, if the seasonal applied to money demand $\left(S_{t}\right)$, but not to the real interest rate $\left(T_{t}\right)$, then the seasonal in monetary growth would eliminate the seasonal in inflation along with that in the nominal interest rate. But, if there is a seasonal in the real interest rate, then a seasonal in inflation remains.

Since the seasonals in money demand and the real interest rate were assumed to be deterministic and understood by the monetary authority, the seasonal in the nominal interest rate could be eliminated by introducing a deterministic seasonal into monetary growth. More generally, the seasonals 
in money demand and the real interest rate could evolve stochastically, and also be unknown to the monetary authority. But, even in this case, the policymaker could remove the seasonal in the nominal interest rate by pursuing the type of feedback reaction to the nominal interest rate that was considered before. Hence, if the elimination of seasonals in nominal interest rates is deemed to be desirajle (on public-finance grounds?), then the possibility of removing them in this way strengthens the case for interest-rate targeting.

\section{Empirical Findings}

The empirical results involve seasonally unadjusted data since 1890 on nominal interest rates (4- to 6 -month prime commercial paper ${ }^{9}$ ), the monetary base (unadjusted for changes in reserve requirements), the consumer price index (CPI-U, available since 1913, except that the index without the shelter component was used since 1970), and the producer price index (PPI, all commodities). All variables are monthly but observed at the quarterly intervals of January, April, July, and 0ctober. The identification of the period in the theory with quarters is: of course, somewhat arbitrary. (Recall that the period in the theory relates especially to the flow of information about the price level.)

The underlying data are monthly averages of daily figures for interest rates and the menary base (except that before August 1917 the figures on the monetary base are at the end of each month). The price indices are an average of observations during each month, although for the CPI some of the components are sampled less frequently than once per month. The 3 -month spacing between each observation should minimize the problems related to 
time-averaged data. That is, the formulation approximates point-in-time data observed once per quarter.

Figures 1-4 depict the four time series under study. 10 All variables are measured at annual rates. Figure 1 shows the nominal interest rate at a quarterly interval from 1860 to 1987 . The interest rate displays more high frequency movement before 1914 (when the Fed was established) than afterwards. As noted by Macaulay (1938, Chart 20), Shiller (1980, pp. 136-137), Miron (1986), Clark (1986), and Mankiw, Miron, and Weil (1986), among others, this pattern turns out to reflect seasonals and other temporary movements in the nominal interest rate that were much more important during the earlier period than later on. In addition, the nominal interest rate appears to be stationary in the earlier sample and non-stationary in the later one. Note also that the graph shows the extremely low nominal interest rates from the mid 1930s to the early 1950s, which includes the period of explicitly pegged Treasury Bill rates from April 1942 to mid 1947 (and with a moving peg from then to the Fed-Treasury Accord of March 1951 and its confirmation by the Fed in March $1953^{11}$ ). However, it is unclear from the graph whether this pegging involves a special policy or was instead just the consequence of the nominal interest rate coming close to its lower bound of zero. Probably it is no accident that the period of precise pegging coincides with the time of lowest nominal interest rates.

Figure 2 shows the growth rate of the monetary base at a quarterly interval from 1879 to 1987 . The growth rate for each quarter is expressed at an annual rate. For the entire sample period, the plot indicates a great deal of high frequency variation, which turns out to reflect seasonals and other temporary fluctuations. Unlike for the nominal interest rate, it is 
less clear visually what sort of break in the monetary process might have occurred around 1914.

Figure 3 shows the annualized growth rate of the consumer price index at a quarterly interval from 1913 to 1987. Similarly, Figure 4 indicates the growth rate of the producer price index at a quarterly interval from 1860 to 1987. The decreasing volatility of each series over time probably reflects, at least in part, the increasing coverage of goods.

Table 1 contains regression results for the recent period, 1954.1 to 1987.4. Starting in 1954 avoids the extremely low nominal interest rates through the early 1950s, for which the lower bound of zero sould be significant (so that nominal interest rates could not be approximated as a random walk). Also, this sample excludes any effects on measured price indices from the controls during World War II and the Korean War.

The basic format of the empirical results consists of estimated equations for an ARMA representation with systematic seasonals,

$$
\text { (30) } \begin{aligned}
Y_{t}=q_{1} S_{1 t} & +q_{2} S_{2 t}+q_{3} S_{3 t}+q_{4} S_{4 t}+\rho Y_{t-1} \\
& +e_{t}+c_{1} e_{t-1}+c_{2} e_{t-2}+c_{3} e_{t-3}+c_{4} e_{t-1}
\end{aligned}
$$

where $e_{t}$ is a white-noise error and $Y_{t}$ represents $R_{t}, \Delta M_{t}, \Delta P_{t}$, or $\Delta(P P I)_{t}$. ( $R$ is the commercial paper rate, $\Delta M$ is the growth rate of the monetary base, $\triangle P$ is the growth rate of the CPI, and $\triangle(P P I)$ is the growth rate of the producer price index. ${ }^{12}$ ) The variable $S_{1 t}$ is a seasonal dummy for the first quarter ( 1 for January, 0 otherwise), and similarly for $S_{2 t}$ (for April), $s_{3 t}$ (for July), and $S_{4 t}$ (for 0ctober). For $R_{t}$ as the dependent variable, the 
hypothesis under a regime of interest-rate smoothing is $q_{1}=q_{2}=q_{3}=q_{4}=0$ (or possibly a constant), $\rho=1, c_{1}=c_{2}=c_{3}=c_{4}=0$. For $\Delta \mathrm{M}_{\mathrm{t}}, \Delta \mathrm{P}_{\mathrm{t}}$, and $\Delta(\mathrm{PPI})_{t}$, the model under interest-rate smoothing suggests nonzero values for $q_{1}, q_{2}, q_{3}$, and $q_{4}, \rho=1, c_{1} \leq 0$, and $c_{2} \geq 0$, with $\left|c_{1}\right|$ much greater than $c_{2}$ and $c_{1}+c_{2} \geq-1$. Hore generally, the theory suggests that the moving-average coefficients will be negative and of substantial magnitude over the near term ( $\operatorname{such}$ as $c_{1}$ ), and positive but of much smaller size later on.

Aside from the estimated coefficients and (asymptotic) standard errors, the table reports the following statistics:

Q(10): Box-Pierce Q-statistic for serial correlation of residuals with 10 lags, with degrees of freedom and asymptotic significance level (based on the $x^{2}$ distribution) shown in parentheses.

Seasonals: Iikelihood-ratio statistic (equal to $-2 \bullet \log$ of likelihood ratio) for the equation with seasonals against the null hypothesis of the same equation except for no seasonality $\left(q_{1}=q_{2}=\right.$ $q_{3}=q_{4}$ ), with the asymptotic significance level (based on the $x^{2}$ distribution with 3 degrees of freedom) shown in parentheses.

The random-walk model, $R_{t}=R_{t-1}+$ constant (where the constant could be set to zero here), is satisfactory for the nominal interest rate in the post- 1954 period. Notably, $Q(10)$ from line 1 of Table 1 has a significance level of .18 , while the likelihood-ratio statistic for seasonals has a significance level of $.67 .^{13}$ The unrestricted estimate of $R_{t-1}$ is .934 , s.e. $=.030$. The implied "t-value" relative to unity is 2.2 , which is below the .10 critical value of 2.6 from the Dickey-Fuller test (Fuller, 1976, Table 8.5.2, the section for $\tilde{\tau}_{\mu}$ ). Given the random-walk-like behavior of the 
nominal interest rate, the theory's other predictions should apply to monetary-base growth and inflation.

The estimated equation in the ARIMA $(0,1,2)$ form for the growth rate of the monetary base appears in line 4 of the table. The equation exhibits strong seasonality, with a likelihood-ratio statistic of 109 . The

Q-statistic for serial correlation of residuals is 9.2 , which is significant at only the .33 level. The estimated $M A(1)$ coefficient is highly

significant, -.79, s.e. $=.09$, and conforms in sign and rough magnitude with the model's predictions. Corresponding to an $\mathrm{MA}(1)$ value of -.79 , the model implies $0 \leq \mathrm{MA}(2) \leq .25$. The estimated $M A(2)$ coefficient on line 4 is -.07 , s.e. $=.09$, which is insignificantly below zero, but significantly less than .25 .

Line 6 of the table shows that the inclusion of more moving-average terms leads to an estimated $M A(4)$ coefficient of .15 , s.e. $=.09$. Thus, the results accord with the prediction that the moving-average terms will be negative and large in magnitude over the near term (lag 1), and positive but small in size later on (in this case at lag 4 , but not at lags 2 or 3 ). Lines 5 and 7 show that freely estimated coefficients of $\Delta \mathrm{m}_{\mathrm{t}-1}(.990, \mathrm{~s} . \mathrm{e} .=$ .098 , and .952 , s.e. $=.114$, respectively) differ insignificantly from one according to the Dickey-Fuller test. ${ }^{14}$

The ARIMA $(0,1,2)$ form for the CPI inflation rate appears on line 9 of Table 1. The seasonals are again significant, although less dramatically than for the monetary base. The 0 -statistic is now significant at the .07 leve1. The estimated $M A(1)$ coefficient, -.66 , s.e. $=.09$, again accords with the theory. Corresponding to $M A(1)=-.66$, the theory predicts $0 \leq \mathrm{MA}(2) \leq .20$, which is consistent with the estimated value for MA(2) of 
.09 , s.e. $=.09$. The inclusion of more moving-average terms on line 11 leads to $\mathrm{MA}(3)=.26$, s.e. $=.09$. Finally, lines 10 and 12 show that freely estimated coefficients for $\Delta p_{t-1}$ are insignificantly different from one $(.944$, s.e. $=.074$, and .870, s.e. $=.088$, respectively).

The underlying theory regarded the nominal interest rate as controllable by the monetary authority, but treated the expected real interest rate as exogenous with respect to monetary variables. Hence monetary policy affected the nominal interest rate only by influencing the expected rate of inflation. Many economists are skeptical abont this model because they think of nominal interest rates as highly flexible and of actual and expected inflation rates as sticky in the short run. The results in Table 1 conflict with this view in that the residual standard deviation for quarterly CPI inflation-2.4\% per year on line 9 -is about double that of the nominal interest rate-1.2\% per year on line 1. Similarly, as the theory predicts, the residual standard deviation for monetary base growth-3.3\% per year on line 4 -exceeds that for the nominal interest rate. 15

Table 2 shows comparable results for the interwar period, 1922.1-1940.4. There is now some indication of predictable movements in the nominal interest rate. For example, in line 2 of the table, the estimated MA(1) coefficient is .24, s.e. $=.12$, and the likelihood-ratio statistic for the seasonals has a significance level of .04 . However, the seasonal coefficients are small in magnitude. The unrestricted estimate of $\mathrm{k}_{\mathrm{t}_{-}-1}$ on line $3-.949$, s.e. $=.029$ again differs insignificantly from one. 0verall, these results for the interest rate turn out to be a middle ground between those shown in Table 1 for the post-1954 period and those examined below for the pre-1914 period, which reveal substantial predictable movements in the nominal interest rate. 
The ARIMA $(0,1,2)$ process for monetary-base growth, shown on line 5 of Table 2, again exhibits pronounced seasonality, although the pattern differs from that for the post- 1954 period. The $M A(1)$ coefficient is substantially negative $(-.66$, s.e. $=.12)$, but the new element is the significantly negative $\mathbf{M A}(2)$ value $(-.28$, s.e. $=.12)$. Even with the inclusion of more moving-average terms (line 7), the results do not reveal the eventually positive terms predicted by the theory. However, the coefficients of $\Delta \mathrm{m}_{\mathrm{t}-1}$ (lines 6 and 8 ) still differ insignificantly from one.

For CPI inflation, the ARIMA $(0,1,2)$ process on line 10 looks similar to that estimated for the post-1954 period. There is, however, no appearance of positive MA coefficients at longer lags (line 12). The estimated coefficients for $\Delta p_{t-1}$ (lines 11 and 13) still differ insignificantly from one.

Table 3 shows results for the period 1890.1-1913.4, which applies to the gold standard and precedes the founding of the Federal Reserve. For this period the nominal interest rate may be stationary and a coefficient of zero for $R_{t-1}$ is satisfactory (lines 2 and 3 of the table). However, the estimated coefficient of $R_{t-1}$ on line $3-.16$, s.e. $=.37$-also differs insignificantly from one according to the .10 critical value of the Dickey-fuller test. There is now substantial short-run predictability of movements in the nominal interest rate; in line 2 the likelihood-ratio statistic for seasonality has a significance level of .001. In addition, the first three $M A$ coefficients are positive and significant $(.49$, s.e. $=.11$; .22 , s.e. $=.11 ;$ and .26 , s.e. $=.11)$.

Given the absence of interest-rate smoothing, the behavior of the monetary base and the price level before 1914 should differ from that found 
in the later periods. The results suggest that the growth rate of the monetary base before 1914 (which coincides in this period with currency in circulation) is stationary, and a coefficient of zero for $\Delta m_{t-1}$ is satisfactory (lines 5 and 6 of Table 3 ). (The estimated coefficient of $\Delta \mathrm{m}_{\mathrm{t}-1}$ is -.21 , s.e. $=.36$; which differs sigrificantly from 1 at about the .01 level according to the Dickey-Fuller test.) There are significant seasonals in monetary-base growth, as shown on line 5 by the significance level of .000 for the likelihood-ratio statistic. ${ }^{16}$ However, this seasonal in the monetary base did not eliminate the seasonal in tie nominal interest rate. In fact, since the linited States was on the gold standard, the behavior of the monetary base (and the U.S. price level) would have been largely constrained to be consistent with the world price level, including its seasonal pattern if it had one. Therefore, it would not generally be possible under this type of monetary system to choose a seasonal in the monetary base that removed the seasonal in the nominal interest rate.

Aside from the seasonals, the results for the growth rate of the monetary base on line 5 indicate a positive $M A(1)$ coefficient, .28, s.e. $=.11$. The simple specification that monetary-base growth is an $\mathrm{MA}(1)$ with seasonals appears satisfactory according to the Q-statistic.

Viewed jointly, the results for the nominal interest rate and the monetary base in Tables $1-3$ are consistent with the viewpoint (expressed recently by Mankiw, Miron, and Weil, 1986) that shifts in monetary policy after the founding of the Federal Reserve in 1914 were responsible for the elimination of predictable temporary movements, including seasonals, in the nominal interest rate. The present analysis identifies these shifts in monetary policy with specific changes in the process for monetary-base 
growth. Namely, the growth rate became non-stationary, a substantially negative MA(1) coefficient appeared, and the seasonal patterns changed. Moreover, the results for the interwar period suggest that the Federal Reserve did not get the monetary process right immediately. Only in the post-1954 period does all the short-term predictability of nominal interest rate movements seem to disappear. On the other hand, the results are consistent with the idea that the elimination of a serious gold standardalso occurring in 1914-was responsible for the changed behavior of nominal interest rates. The elimination of the gold standard may have been a prerequisite for the implementation of a monetary policy that successfully targeted nominal interest rates. 17

Results for the PPI inflation rate from 1890 to 1913 appear on Iines 7 and 8 of Table 3 . This inflation rate exhibits significant seasonality and appears to be stationary (the estimated coefficient of $\Delta p_{t-1}$ on line 8 of Table 3 is .23 , s.e. $=.10$, which is significantly below 1 ). The estimated MA coefficients are insignificant, except for a negative $\mathrm{MA}(4)(-.35, \mathrm{~s} . \mathrm{e}=$ .11), which might reflect stochastic variation in seasonals. The CPI is unavailable for this period, except for rough estimates on an annual basis. (For the later samples, the time-series parameters estimated for PPI inflation accord in a rough way with those for CPI inflation.)

\section{Concluding Observations}

Theoretical reasoning suggests that interest-rate targeting is a reasonable guide for monetary policy. In a model where expected real interest rates and output are exogenous with respect to monetary variables, the central bank influences nominal interest rates by altering expected rates 
of inflation. It turns out that the monetary authority can come arbitrarily close to meeting its (time-varying) target for the nominal interest rate, even while holding down the forecast variance of the price level. The latter objective pins down the extent of accommodation of the money supply to shifts in the demand for money. The greater the variance of shocks to money demand (i.e., of the LH curve) relative to that of the expected real interest rate (i.e., the IS curve), the greater the degree of accommodation.

Incipient increases in the nominal interest rate (caused by shocks to money demand or the expected real interest rate) lead in the usual way to monetary expansion-e.g., to open-market purchases of bonds. This response lowers expected inflation because the influx of money is temporary. That is, the central bank plans to take back later some of today's infusion of money, and people's expectations of this behavior lowers anticipated growth rates of money and prices... Therefore, the nominal interest rate falls back toward its target value even though the expected real interest rate does not change.

If the target nominal interest rate moves as a random walk; the successful targeting by the central bank implies that the nominal interest rate also follows this pattern. Given this policy of interest-rate targeting-and the assumed specification for money demand and the expected real interest rate-the growth rate of the monetary base and the price level must follow ARIMA $(0,1,2)$ processes. The unit roots in these processes reflect mainly the non-stationarity of the nominal interest rate. The moving-average terms correspond to the responses to temporary shocks-in particular, the tendency for infusions of money (in response to incipient rises in the nominal interest rate) to be followed by removal of money in the future. 
Empirical evidence for the United States since 1890 accords in the main with the theoretical propositions. In particular, the results indicate that shifts in monetary policy after the founding of the Fed in 1914 led to the elimination of predictable temporary movements, including seasonals, in the nominal interest rate (on short-term commercial paper). The results identify the changes in monetary policy with specific changes in the process for monetary-base growth. Namely, the growth rate became non-stationary, a substantially negative moving-average term appeared (indicating the tendency for reversals in monetary growth), and the seasonal patterns changed. The results suggest that it was not until the post-1954 period that the Fed smoothed the nominal interest rate in the sense of achieving nearly random- walk like behavior in this rate.

One interesting topic for future research involves applying the model to other countries. At a theoretical level this extension raises questions about the interplay between the exchange-rate regime and the possibilities for independent interest-rate targeting by individual central banks. One issue is why the elimination of predictable short-run movements in nominal interest rates appeared to occur simultaneously around World War I in several industrialized countries (see Clark, 1986, and Mankiw, Miron and Weil, 1986). The founding of the Fed and the elimination of the classical gold standard are possible explanations that are worth exploring.

The empirical work for the United States (or other countries) can be usefully extended to consider in more detail the joint determination of the nominal interest rate, monetary base, and the price level. Such a joint treatment would allow testing of the model's detailed predictions about the cross-relations among the time-series processes. However, these predictions 
tend to be sensitive to parts of the specification-such as the independence of the underlying shocks-that were not crucial for the results obtained thus far. Thus, it will probably be necessary to make the model less restrictive in this respect. With these extensions, it would be possible to estimate parameters, such as the interest-sensitivity of money demand, and the relative variances of the different dissurbances. 


\section{References}

Barro, R.J., "Rational Expectations and the Role of Monetary Policy," Journal of Wonetary Economics, 2, January 1976, 1-32.

" "On the Determination of the Public Debt," Journal of Political Economy, 87, 0ctober 1979, 940-971.

" "A Capital Market in an Equilibrium Business Cycle Mode1," Econometrica, 48, September 1980, 1393-1417.

" "Intertemporal Substitution and the Business Cycle,"

Carnegie-Rochester Conference Series on Public Policy, 14, Spring 1981a, 237-268.

, "Unanticipated Koney Growth and Economic Activity in the

United States," in R.J. Barro, Money, Expectations, and Business Cycles, Academic Press, New York, 1981b.

and R.G. King, "Time-Separable Preferences and "Intertemporal-

Substitution Models of Business Cycles," Quarterly Journal of Economics, 99 , Novenber $1984,817-839$.

Brunner, K., "The Role of Money and Monetary Policy," Federal Reserve Bank of St. Louis, Review, July 1968, 9-24. 
, A. Cukierman, and A.H. Meltzer, "Stagflation, Persistent Unemployment, and the Permanence of Economic Shocks," Journal of Monetary Economics, 6, October 1980, 467-492.

Clark, T.A., "Interest Rate Seasonals and the Federal Reserve," Journal of Political Economy, 94, February 1986, 76-125.

Diller, S.. The Seasonal Variation of Interest Rates, Columbia University Press, New York, 1969.

Fair, R.C., "An Analysis of the Accuracy of Four Macroeconometric Models," Journal of Political Economy, 87, August 1979, 701-718.

Friedman, M., "The Role of Monetary Policy," American Economic Review, 58, March 1968, 1-17.

and A.J. Schuartz, A Monetary History of the Onited States, 1867-1960, Princeton University Press, Princeton, 1963.

Fuller, W.A., Introduction to Statistical Time Series, Wiley, New York, 1976.

Goodfriend, M., "Interest Rate Smoothing and Price Level TrendStationarity," Journal of Monetary Économics, 19, May 1987, 335-348. 
Hetzel, R.L., "A Critique of Theories of Money Stock Determination," unpublished, Federal Reserve Bank of Richmond, January 1987.

Kemmerer, E.W., Seasonal Variations in the Relative Demand for Money and Capital in the United States, U.S. Government Printing Office, Washington, D.C., 1910.

Kimbrough, K.P., "The Optimum quantity of Money Rule in the Theory of Public Finance," Journal of Monetary Economics, 18, November 1986, $277-284$.

King, R.G. and C.I. Plosser, "Money, Credit and Prices in a Real Business Cycle," American Economic Review, 74, June 1984, 363-380.

Lucas, R.E., "Expectations and the Neutrality of Money," Journal of Economic Theory, 4, April 1972, 103-124.

, "Some International Evidence on Dutput-Inflation Tradeoffs," American Economic Review, 63, June 1973, 326-334.

, "Honey in a Theory of Finance," Carnegie-Rochester Conference Series on Public Policy, 21, Autumn 1984, 9-45.

Macaulay, F.R., The lovements of Interest Rates, Bond Yields and Stock Prices in the United States since 1856, National Bureau of Economic Research, New York, 1938. 
Mankiw, N.G., "The Optimal Collection of Seigniorage: Theory and

Evidence," Journal of Monetary Economics, 20, September 1987, 327-341.

, J.A. Miron, and D.N. Weil, "The Adjustment of Expectations to

a Change in Regime: A Study of the Founding of the Federal Reserve," unpublished, Harvard University, 1986.

McCallum, B.T., "Price Level Determinacy with an Interest Rate Policy Rule and Rational Expectations, "Journal of Monetary Economics, 8, November 1981, 319-329.

, "On Non-Uniqueness in Rational Expectations Models: An

Attempt at Perspective," Journal of Monetary Economics, 11, March 1983, 139- 168 .

, "Some Issues Concerning Irterest Rate Pegging, Price Level

Determinacy, and the Real Bills Doctrine, Journal of Monetary

Economics, 17, January 1986, 135-160.

Miron, J.A., "Financial Panics, the Seasonality of the Nominal Interest Rate, and the Founding of the Fed,"American Economic Review, 76, March 1986, 125-140.

Poole, W., "Optimal Choice of Monetary Policy Instruments in a Simple Stochastic Macro Model," Quarterly Journal of Economics, 84, May 1970, 197-216. 
Sargent, T.J. and N. Wallace, "Rational Expectations, the 0ptimal Monetary Instrument, and the Optimal Money Supply Rule," Journal of Political Economy, 83, April 1975, 241-254.

Schwert, G.K., "Tests for Unit Roots: a Monte Carlo Investigation," University of Rochester, January 1987a. , "Effects of Model Specification on Tests for Unit Roots in Macroeconomic Data," University of Rochester, April 1987b.

Shiller, R.J., "Can the Fed Control Real Interest Rates?" in S. Fischer, ed., Rational Expectations and Economic Policy, University of Chicago Press, Chicago, 1980.

U.S. Department of Labor, Index of tholesale Prices on Pre-Nar Basis, U.S. Government Printing Office, Washington, D.C., 1928.

Warren, G.F. and F.A. Pearson, Prices, Wiley, New York, 1933. 


\section{Footnotes}

*Th is research is supported by the National Science Foundation: I have benefited from comments by Marvin Goodfriend, Bob King, Greg Mankiw, Allan Meltzer, Ben McCallum, and Bill Schwert.

${ }^{1}$ Since $m_{t}$ refers to the monetary base, the money-demand shocks could reflect shifts in reserve requirements or in other financial regulations. In this broader sense, monetary policy can alter the quantity of real money demanded at a giver nominal interest rate. But these kinds of policies are not considered here.

${ }^{2}$ Lucas (1984) views the tax rate on money as a determinant of the relative cost of cash and credit goods. Therefore, if the tax rate on final output is set optimally; it is unclear that the tax rate on money should be positive-that is, that money-using goods should be taxed more heavily than credit- (or barter-) using goods.... (For a similar argument, see Kimbrough, 1986.) However, a positive tax rate on money does allow the government to tax some black-market activities where final product is not taxed. Also, if the main existing taxes are on some of the factor inputs, especially labor, then it may be desirable to tax other inputs, such as monetary services.

${ }^{3}$ Given that $p_{t}$ is not observed at date $t$, it is possible that $p_{t}$ should be replaced by $E_{t} p_{t}$ in equation (1). However, in a setting such as Barro (1976), equation (1) can arise as the aggregation over local markets, each of which observes the current local price, $p_{t}(z)$. 
${ }^{4}$ It would be possible to assume that the monetary authority knows $\bar{R}_{t}$ but the private sector does not. However, ir the present model, the equilibrium value for $R_{t}$ would reveal $\vec{R}_{t}$ anyway.

${ }^{5}$ Because $\alpha_{t-1}$ is observable at date $t$, the lagged price level, $p_{t-1}$, turns out not to enter in equation (5).

${ }^{6}$ Shiller (1980, p. 130) recognizes this possibility but regards it as implausible: "We usually think that increasing high-powered money is, if anything, a signal of higher inflation. It would seem implausible, then, that these lower interest rates are due to lower inflationary expectations. It is conceivable that exogenous increases in the money stock might be a sign of lower inflation over a certain time horizon if the parameters of our model were just right." In the present model the parameters turn out to "just right" as a consequence of the monetary authority's optimizing behavior.

${ }^{7}$ I use McCallum's $(1983,1986)$ procedure for selecting the unique bubble-free solution.

${ }^{8}$ The choice $\lambda_{3}+\infty$ seems also to work. However, $\lambda_{3} \geq(1+\beta)$ can be ruled out on grounds discussed by McCallum (1986, p. 140, n.7). In particular, if $\lambda_{3} \geq(1+\beta)$, then the realization of a shock-say $\eta_{t}$-causes an unstable dynamic response of the price level.

${ }^{9}$ Results for the nominal interest rate are similar with the 3 -month time loan. rate used by Mankiw, Miron and Weil (1986). 
${ }^{10}$ The nominal interest rate applies to 4 - to 6 -month commercial paper (6-month paper in recent years), as reported since 1890 in U.S. Board of Governors of the Federal Reserve System, Banking and Monetary Statistics; Banking and Monetary Statistics, 1941-1970; Annual Statistical Digest, 1970-1979 and later issues; and the Federal Reserve Bulletin. Earlier data, from Macaulay (1938, Appendix Table 10), refer to 60-90 day commercial paper. (These were adjusted upward by .014 to nerge with the other series in 1890.) The monetary base since 1914 comes from the Federal Reserve sources noted above. Earlier data come from the National Bureau of Economic Research.. The CPI since 1913 is from the Bureau of Labor Statistics. (CPI-U, with the CPI less shelter used since 1970 to avoid problems with mortgage interest costs). The PPI (all commodities) since 1913 comes from the Bureau of Labor Statistics. Data from 1890 to 1912 are from U.S. Department of Labor, 1928 (kindly provided by Jeff Miron). Data before 1890 are from Warren and Pearson, 1933, Table 1 .

${ }^{11}$ For a discussion of the Accord, see Friedman and Schwartz, 1963, pp. $623 f f$.

${ }^{12}$ Schwert (1987b, Table 9) shows that an ARIMA $(0,1,4)$ process works well on seasonally adjusted monthly data for the growth rate of the monetary base, CPI inflation, and PPI inflation.

13 Weak evidence of seasonality in the nominal interest rate appears in some sub-samples of the post- 1954 period-for example, for 1954.1-1959.4 and the $1970 \mathrm{~s}$. However, the seasonals look very different for these two periods. The seasonal found for the 1954-1959 period seems to be consistent with the results of Diller $(1969$, Ch. 3$)$. 
${ }^{14}$ Schwert's (1987a, Table 3) Monte Carlo results indicate that the Dickey-Fuller test for a unit root works well if the underlying process is ARIMA $(0,1,1)$. Therefore this test should be appropriate in the present context.

${ }^{15}$ The estimated residual standard errors for inflation and monetary growth correspond to $\sigma_{f}$ and $\sigma_{e}$ for equations (22) and (19), respectively. The corresponding standard errors for $\mathrm{F}_{\mathrm{t}}$ and $\mathrm{E}_{\mathrm{t}}$ are .028 and .042 , respectively. These values each exceed the residual standard error for the nominal interest rate, .012 , as predicted by the theory.

${ }^{16}$ I have made no adjustment here for the fact that the end-of-month data before August 1917 apply to different days of the week. The finding of significant seasonals in monetary-base growth before 1914 accords in a general way with Kemmerer (1910, Ch. 6), but seems to conflict with results reported by Clark (1986, pp. 106ff.).

${ }^{17}$ Clark (1986, pp. $\left.85 \mathrm{ff}.\right)$ points out that the main seasonal in nominal interest rates ended at about the same time-around 1914-in a number of industrialized countries. This outcome accords with the idea that the ending of the gold standard freed up all the central banks simultaneously. However, it would be worthwhile to examine the changes in the monetary processes for the various countries. Also, it is worth considering whether interest-rate targeting by more than one country is feasible under fixed exchange rates (even in the absence of a serious gold standard). 


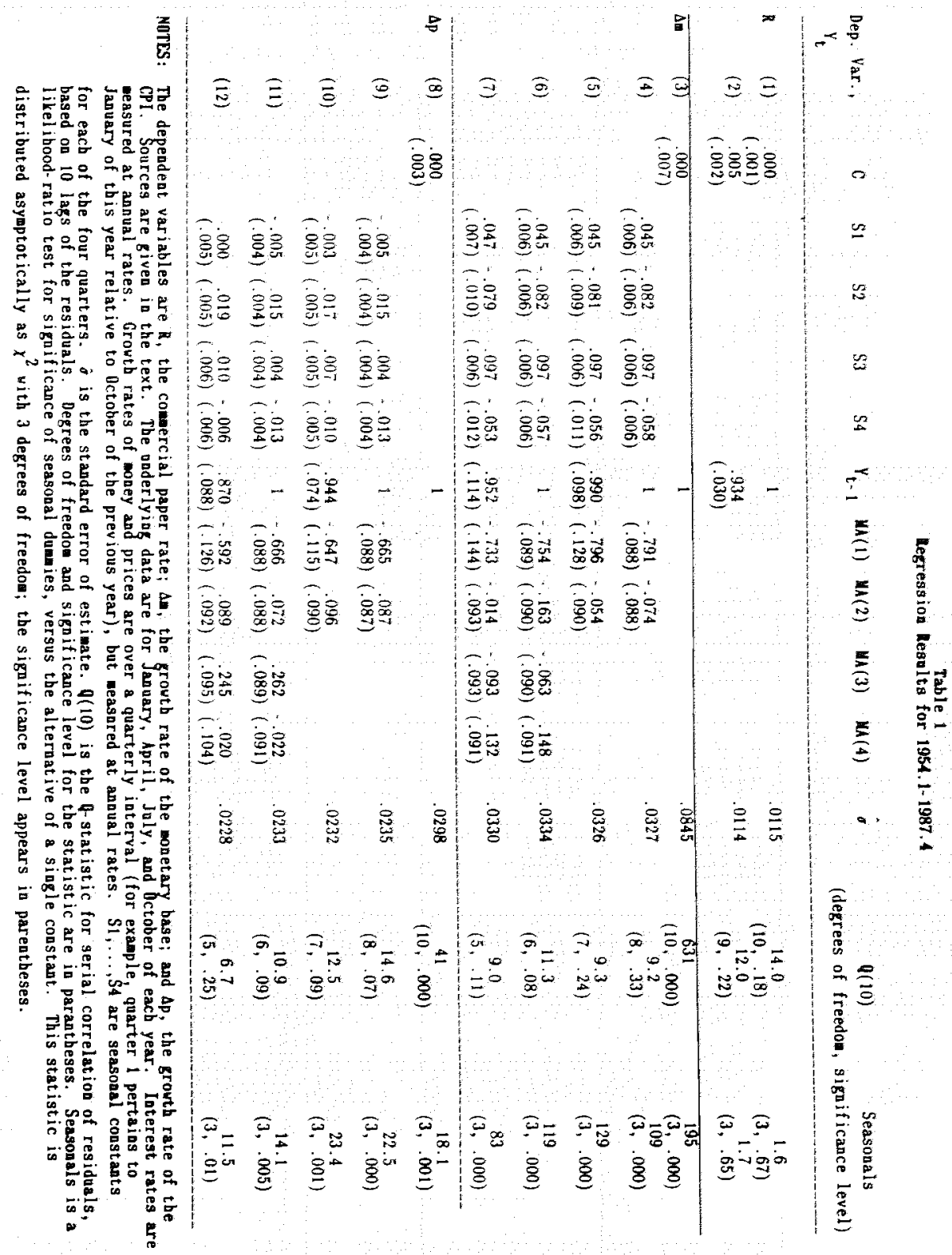




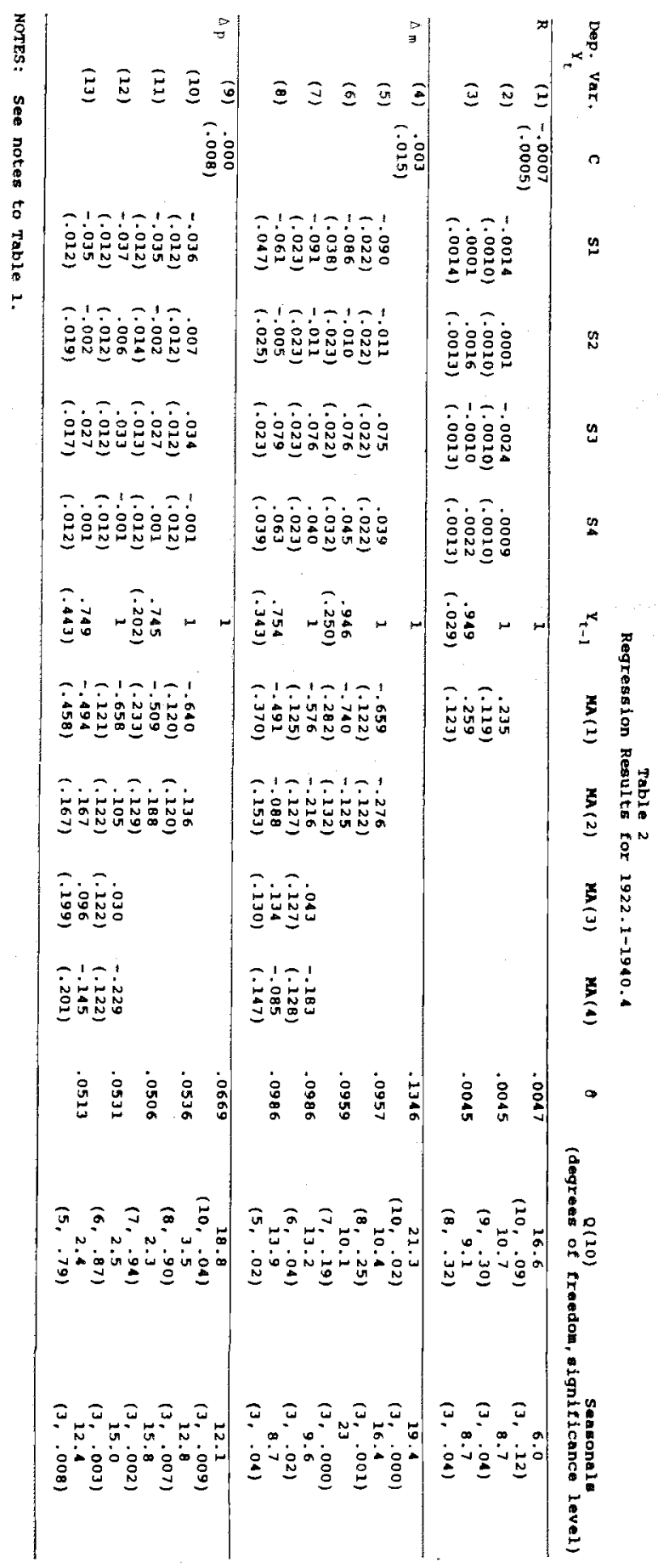




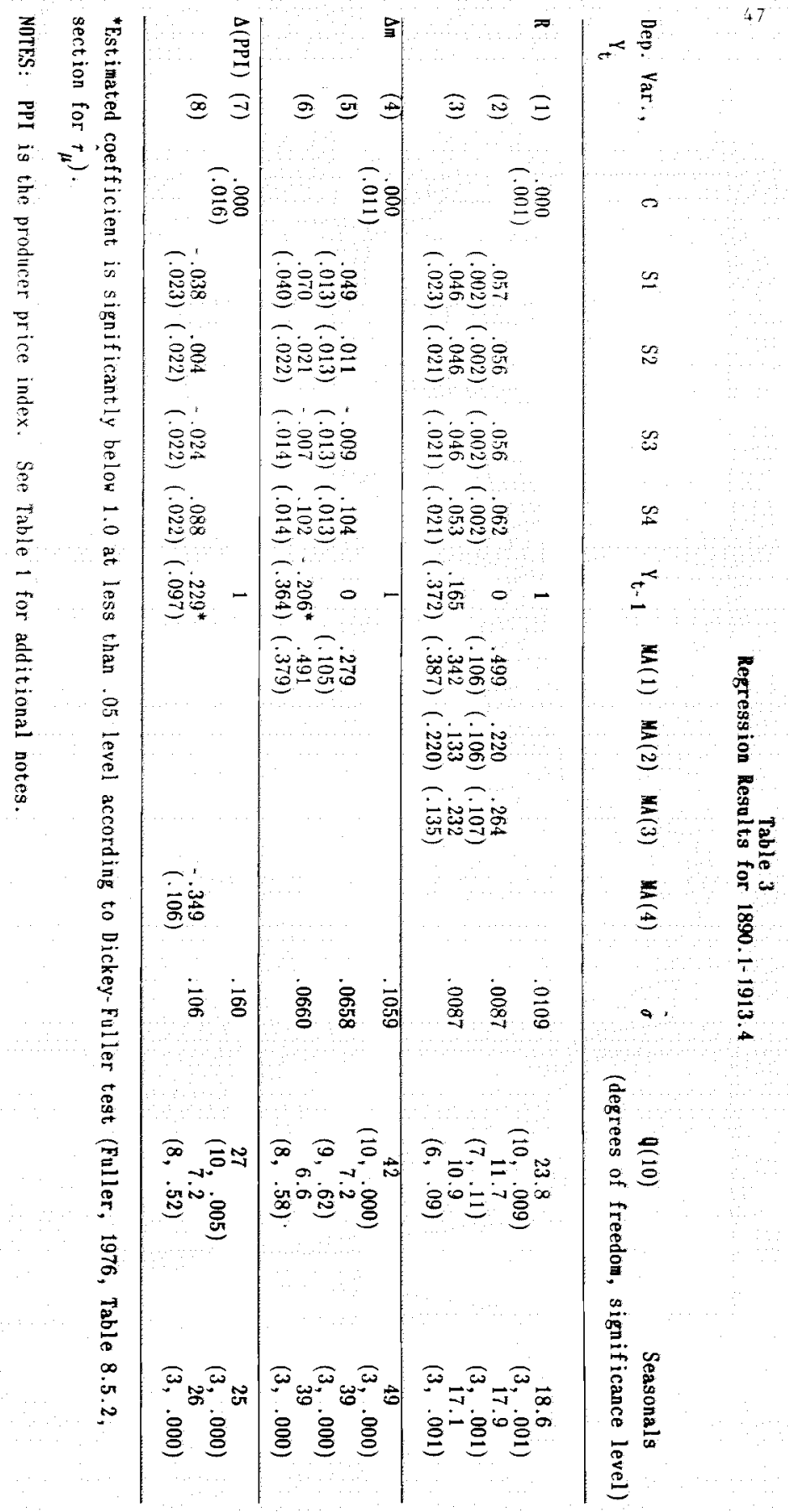




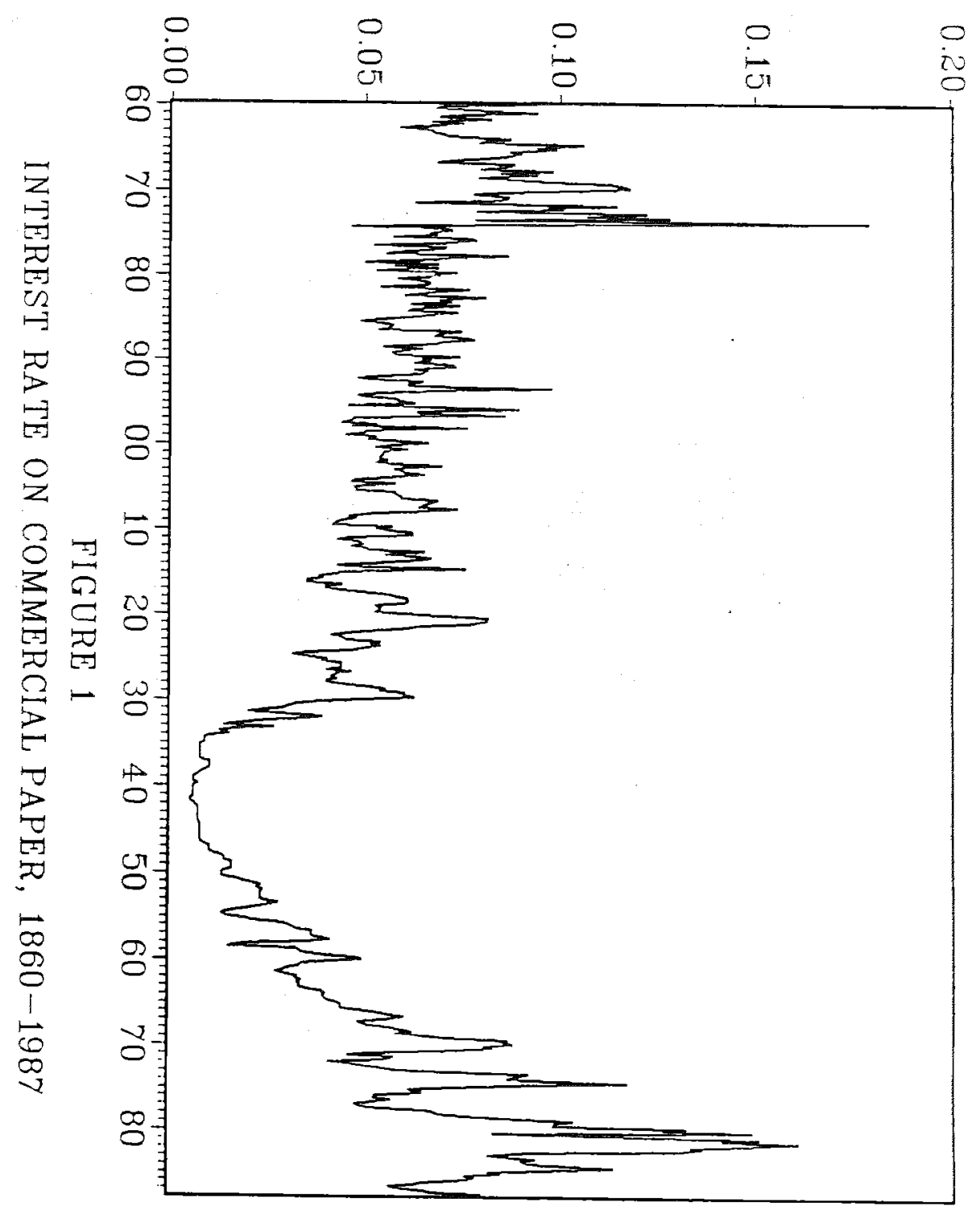




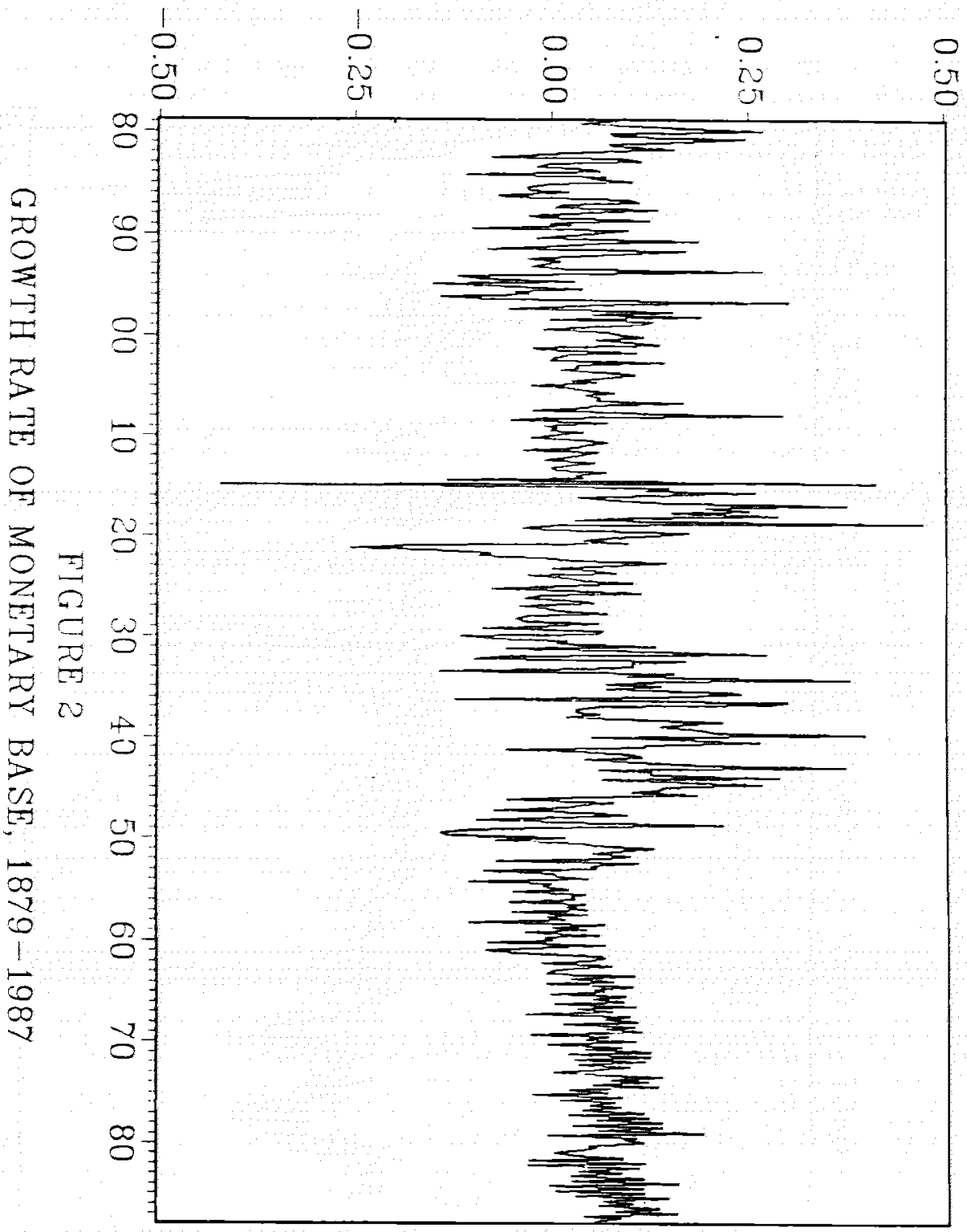




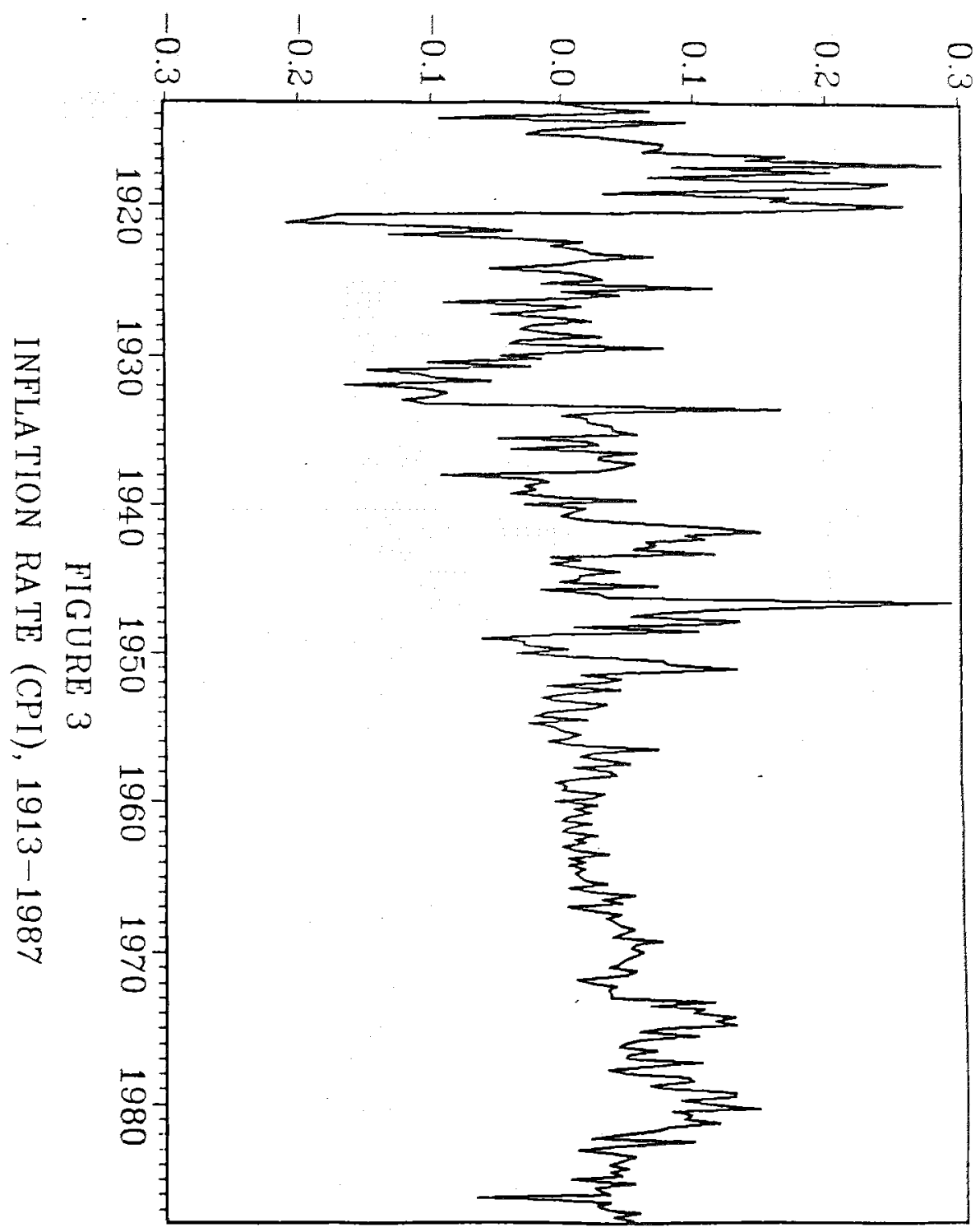




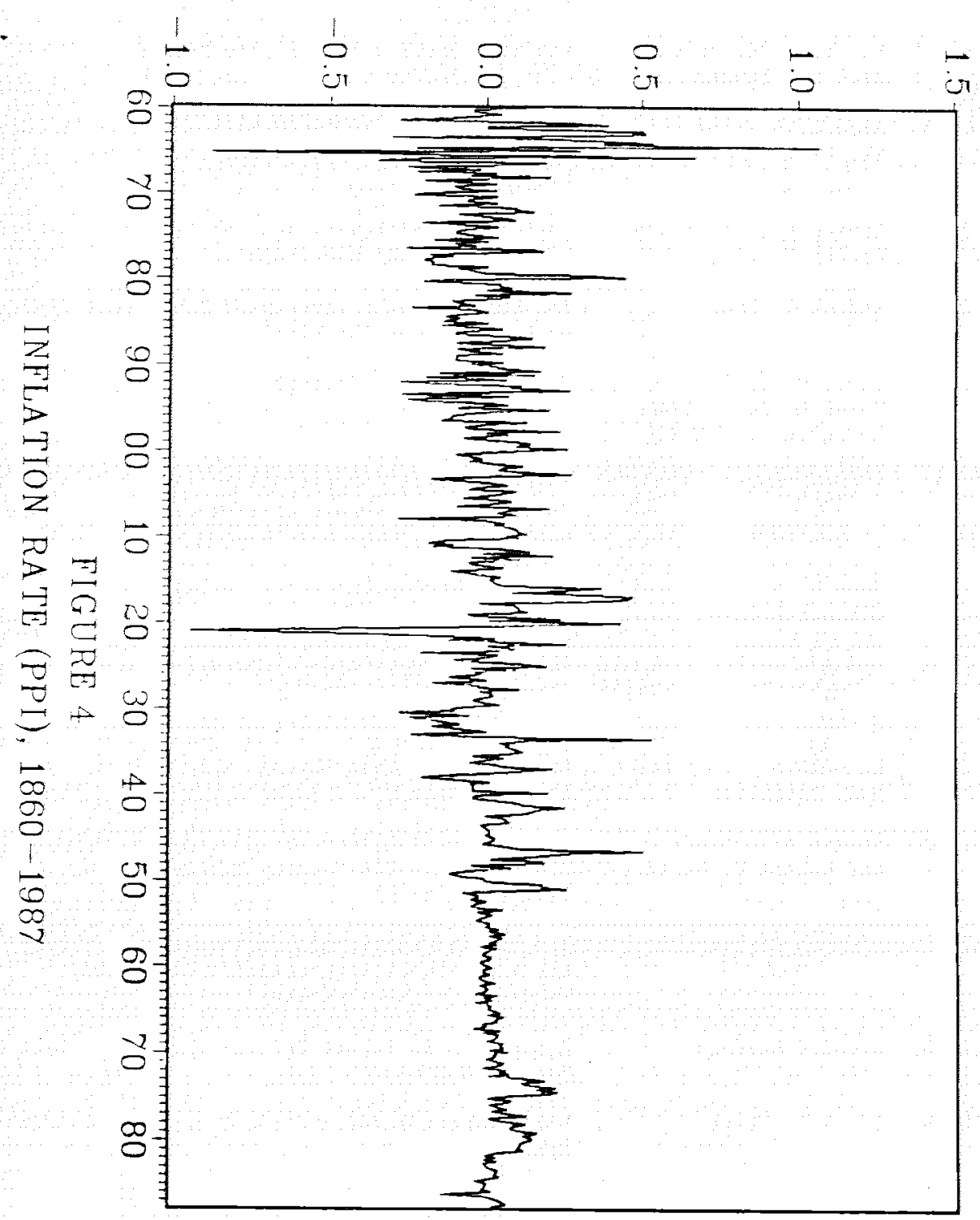

